\title{
Biosafety code gathers pace through bilateral agreements
}

London. Argentina last week became the first developing country to adopt internationally agreed safety guidelines covering the transportation and use of genetic engineering products that are being developed under the auspices of the United Nations Environment Programme (UNEP).

The move took the form of a bilateral agreement signed on 8 September in Buenos Aires by Britain's environment secretary, John Gummer, and Felix Cirio, Argentina's undersecretary of state for agriculture, livestock and fisheries. As part of the agreement, Britain will help Argentina to build up its expertise in biosafety, and the two countries will hold a joint workshop on the topic early next year.

A similar agreement is expected to be signed in the near future between Costa Rica and the government of the Netherlands. Britain and the Netherlands were the main countries responsible for drawing up the original draft of the guidelines, which some see as an alternative to a legally binding international treaty on biosafety; Gummer described the Argentine agreement as "an important stop towards the safe application of biotechnology".

The move will put new pressure on those countries keen to see a formal international protocol, which signatories to the UN Convention on Biological Diversity, approved by the UN Earth Summit in Rio de Janeiro in 1992, have already agreed to explore.

A draft protocol has been drawn up by a panel of experts, in line with a decision passed at the first meeting of the convention's signatories held in the Bahamas last November (see Nature 372, 585; 1994). It was discussed at a UNEP biosafety meeting in Madrid in July, whose recommendations will now be put to the convention's signatory countries in Jakarta in November.

But although some UN members are enthusiastic about a legally binding protocol, others are more sceptical. The United States, Germany and Australia, for example, have all expressed strong reservations, concerned that signatories would be required to impose excessively rigid legislation on their domestic industry.

Members of a third group, which includes several European countries - in particular Britain and the Netherlands - say they support the idea of a protocol. But they also claim that the length of time required for such a document to be agreed, signed, ratified and subsequently implemented suggests that voluntary guidelines offer an alternative approach that should be pursued in parallel.

This was the spirit in which the guidelines were originally drawn up by Britain and the Netherlands in 1993. They cover a wide spectrum of topics, ranging from agreement on the principal of risk assessment and risk management to the identification of bodies responsible for implementing safety regulations at both a regional and a national level.

The guidelines also specify mechanisms to be put in place to ensure that the transfer of genetically manipulated organisms between countries is accompanied by the appropriate information, a condition which officials say will provide useful guidance to researchers wishing to exchange material between laboratories in different countries.

Finally, in a move partly designed to increase the attraction of the guidelines to developing countries in which industrial nations seek to establish markets for their biotechnology products, the text specifies that the latter will help the former to develop "human resources, training and institutional capacities in order to achieve maxiumum benefit from biotechnology".

To the clear satisfaction of both British and Dutch officials, international discussion on the guidelines - whose implementation will remain voluntary on both sides, leaving it to the country concerned to decide whether and if so how its commitments will be enshrined in legislation - was taken over at the end of last year by UNEP, which says that they are entirely compatible with parallel efforts on a binding protocol.

The European officials now hope that Argentina and Costa Rica will be the first of many developing and newly industrializing countries that will agree to sign up. This will help such countries, they say, to attract foreign investment from pharmaceutical and other biotechnology companies.

Several countries in South-East Asia, for example, which have recently been making a substantial investment in their domestic biotechnology efforts, and are keen to open up markets for the results of such efforts in the West, are believed to be among those currently considering whether to do so.

Public opinion in Argentina has been sensitive to biotechnology safety ever since strong international criticism was voiced in the early 1980s of experiments with a genetically engineered vaccine against foot and mouth disease. The Argentine officials are therefore keen to display their social responsibility by agreeing to the UNEP guidelines.

UNEP has recently completed a series of regional meetings on the draft guidelines, and is preparing a final, global consultation at which supporters of the guidelines hope that international consensus - even given continuing claims from environmental groups that a voluntary approach to biosafety is insufficient - will be reached on both their value and content.

David Dickson

\section{Russian scientists threaten campaign of protests over funding}

Moscow. Scientists from the Far Eastern branch of the Russian Academy of Science, which is based in Vladivostok, have threatened a campaign of civil disobedience in protest at the lack of funding from the central government.

In a letter addressed to President Boris Yeltsin at the end of last month, members of the trade union committee of the academy said that they there were issuing a "last warning" to the leadership of the country about their plight.

"If political leaders do not pay attention to our problems and start observing the law on those parts of the budget that deal with the financing of science, we shall reserve the right to take the most extreme actions," wrote the scientists.

Committee members complained at a press conference in Vladivostok on 30 August that science in the Far Eastern region of Russia is in danger of disappearing completely due to a continuing shortage of funds, research materials and technical support.

As an example, committee members point out that marine biologists in the area are unable to carry out any research because a lack of funds means that the scientific fleet is not in operation.

Veniamin Myasnikov, deputy chairman of the Far Eastern branch of the academy, says one of the major problems is that being so far from other cultural centres, science in the region is relatively undeveloped, and most scientists have come from western or central parts of Russia.

As a result, unlike their colleagues in other cities, those who lose their job in a research institute or laboratory find it necessary to return home, as they cannot afford to take on temporary work while awaiting for new research funds to arrive.

Myasnikov claims that their departure only makes the situation worse for those who stay behind. "When the most qualified people, whom we had been pleased to welcome to Vladivostok many years ago, begin to abandon it, they leave behind an intellectual desert," he says.

The situation is not entirely bleak. According to Myasnikov, scientists at his institute have been able to win contracts from outside commercial bodies such as banks, factories and even local stock exchanges for setting up computerized control systems.

But Myasnikov admits scientists in other disciplines, such as geology, are less fortunate because their skills are in less demand from the private sector - one reason that geologists were the main organizers of last month's protest.
Carl Levitin 